\title{
Investigation of Synthesis of Sodium Aminodiborane in One Step and Its Reaction Kinetics
}

\author{
Meryem Sena Akkuş ${ }^{1,2, *}$, Göksel Özkan² \\ 'Ankara Yıldırım Beyazıt University, Central Research Laboratory Application and Research Center, 06010, \\ Keçiören, Ankara, Turkey \\ ${ }^{2}$ Gazi University, Faculty of Engineering, Chemical Engineering Department, 06570, \\ Maltepe, Ankara, Turkey
}

*Corresponding author email: msakkus@ybu.edu.tr

Received July 15, 2020; Accepted October 08, 2020; Available online November 20, 2020

\begin{abstract}
In this study, sodium aminodiborane $\left(\mathrm{NaNH}_{2}\left(\mathrm{BH}_{3}\right)_{2}\right)$ synthesis was carried out in a constant volume batch reactor with a single feed at various temperatures and inlet molar ratios. It was synthesized, ammonia borane and sodium hydride as precursors, by a wet chemical reaction method using tetrahydrofuran which is a solvent under atmospheric pressure. These experiments were carried out at varied temperature ranges from $0{ }^{\circ} \mathrm{C}$ to $24{ }^{\circ} \mathrm{C}$, and varied inlet molar ratios $(A B / N a H)$ from 0.75 to 1.25. Sodium amidoborane is synthesized when the experiment is carried out in a stoichiometric ratio, but sodium aminodiborane is synthesized when the mole of ammonia borane is higher than the mole of sodium hydride. In order to characterize the products, FTIR, XRD, GC-MS/MS, and quantitative analysis techniques were utilized. In addition, sodium aminodiborane's synthesis reaction kinetic was determined. $r_{\text {apparent }}=0.8594 \mathrm{e}^{-\frac{4366}{\mathrm{RT}}} \mathrm{C}_{\mathrm{AB}}^{0.8} \mathrm{C}_{\mathrm{NaH}}^{0.2}$. The apparent activation energy, $E_{a}$, and frequency constant, $\mathrm{k}_{0}$, were calculated about $4366 \mathrm{~J} / \mathrm{mol}$ and $0.8594 \mathrm{~h}^{-1}$, respectively.
\end{abstract}

Keywords: Hydrogen, hydrogen storage material, sodium amidoborane, sodium aminodiborane, reaction kinetic

\section{INTRODUCTION}

Boron and nitrogen based hydrides such as ammonia borane(Akbayrak \& Özkar, 2018; Keaton, Blacquiere, \& Baker, 2007; Peng \& Chen, 2008; Umegaki et al., 2009), sodium borohydride (Akkuş, Murathan, Özgür, Özkan, \& Özkan, 2018; Brack, Dann, \& Wijayantha, 2015; Liu, Li, \& Suda, 2009; Özkan, Akkuş, \& Özkan, 2019), lithium borohydride (Au \& Jurgensen, 2006; Fan, Chen, Liu, Fan, \& Liu, 2019; Kojima, Kawai, Kimbara, Nakanishi, \& Matsumoto, 2004; Li, Peng, Zhou, \& Wan, 2011; Muthu, Rajashabala, \& Kannan, 2017), hydrazine borane (Hügle, Kühnel, \& Lentz, 2009; Moury et al., 2012; Sutton et al., 2011; Yot et al., 2018; Zhong, Aranishi, Singh, Demirci, \& Xu, 2012) have been investigated to be potential hydrogen carriers in decades because of their high hydrogen contents (Huang \& Autrey, 2012; Umegaki et al., 2009). Among these materials, ammonia borane $(A B)$ has the highest hydrogen concentration ( 19.6\% by wht) (Akbayrak \& Özkar, 2018; Umegaki et al., 2009). However, the main problem needs to be resolved, such as preventing the formation of impurity diborane and borazine during the thermolysis of $A B$. One of the efforts to overcome this problem is metal amidoborane $\left(\mathrm{MNH}_{2} \mathrm{BH}_{3} ; \mathrm{M}=\right.$ alkali metal) synthesis (Owarzany, Leszczyński, Fijalkowski, \& Grochala, 2016). They have been synthesized by reactions of metal hydride or metal amide with ammonia borane. These reactions can be carried out by by two main methods: (I) mechanical a disc/ball milling, and (ii) wet chemical reaction using tetrahydrofuran (abbreviation THF). metal amidoboranes, especially alkaline-earth metal amidoboranes, are synthesized purer via the wet-chemical reaction method (Qiu, Sun, $\& X_{u}, 2015$; Xiong et al., 2008). During the synthesis of them, the potential of the $\mathrm{H}^{+}$in ammonia borane and the $\mathrm{H} \delta$ in metal hydride are interacted to performed. Sodium amidoborane $\left(\mathrm{NaNH}_{2} \mathrm{BH}_{3}\right.$, abbreviation $\mathrm{SAB}, 52.8 \mathrm{~g} / \mathrm{mol}, 7.46 \%$ hydrogen by wt.), lithium amidoborane $\left(\mathrm{LiNH}_{2} \mathrm{BH}_{3}, 36.7 \mathrm{~g} / \mathrm{mol}\right.$, $10.9 \%$ hydrogen by wt.), calcium amidoborane $\left(\mathrm{Ca}\left(\mathrm{NH}_{2} \mathrm{BH}_{3}\right)_{2}, 99.7 \mathrm{~g} / \mathrm{mol}, 10.0 \%\right.$ hydrogen by wt.) and yttrium amidoborane $\mathrm{Y}\left(\mathrm{NH}_{2} \mathrm{BH}_{3}\right)_{3}(178.3 \mathrm{~g} / \mathrm{mol}$, $8.4 \%$ hydrogen by wt.) are examples of metal amidoboranes.

When $S A B$ is compared to ammonia borane, hydrogen production from SAB occurs at lower temperature $\left(90^{\circ} \mathrm{C}\right.$ ) and higher purity (no borazine emission). SAB synthesis reactions are given below (Eq. (1) and Eq. (2)) (Fijałkowski \& Grochala, 2009; Magos-Palasyuk, Fijalkowski, \& Palasyuk, 2016; Sandra, Demirci, Chiriac, Moury, \& Miele, 2011; Weng, Wu, Li, \& Yang, 2012; Xiong et al., 2008).

$\mathrm{NaH}(\mathrm{s})+\mathrm{NH}_{3} \mathrm{BH}_{3}(\mathrm{~s}) \rightarrow \mathrm{NaNH}_{2} \mathrm{BH}_{3}(\mathrm{~s})+\mathrm{H}_{2}(\mathrm{~g})$ 
$\mathrm{NaNH}_{2}(\mathrm{~s})+\mathrm{NH}_{3} \mathrm{BH}_{3}(\mathrm{~s}) \rightarrow \mathrm{NaNH}_{2} \mathrm{BH}_{3}(\mathrm{~s})+\mathrm{NH}_{3}(\mathrm{~g})$

Chen et al, (2015) synthesized sodium aminodiborane $\left(\mathrm{NaNH}_{2}\left(\mathrm{BH}_{3}\right)_{2}, \mathrm{NaABB}\right)$. It takes place in two steps that synthesize $S A B$ and $N a A B B$ in the THF medium. Synthesis temperatures $24^{\circ} \mathrm{C}$ and 60 ${ }^{\circ} \mathrm{C}$, respectively. The reaction of the second step is given in Equation 3. This product is a white color, moreover its solubility is low at THF (Chen, Huang, Wu, \& Chen, 2015).

$$
\mathrm{NaNH}_{2} \mathrm{BH}_{3}(\mathrm{~s})+\mathrm{NH}_{3} \mathrm{BH}_{3}(\mathrm{~s}) \rightarrow \mathrm{NaNH}_{2}\left(\mathrm{BH}_{3}\right)_{2}+\mathrm{NH}_{3}(\mathrm{~g})
$$

Fijalkowski et al. (2014) examined sodium di (amidoborane)borohydride $\left(\mathrm{Na}\left(\mathrm{BH}_{3} \mathrm{NH}_{2} \mathrm{BH}_{2} \mathrm{NH}_{2} \mathrm{BH}_{3}\right)\right.$ which is derivative of $\mathrm{SAB}$. It was carried out inlet molar ratio $A B / N a H=3$ ratio by both mechanical and liquid chemical synthesis methods in the argon atmosphere. They were performed at room temperature for $24 \mathrm{~h}$ (Fijalkowski et al., 2014). The reaction is given in Equation 4.

$\mathrm{NaH}_{(\mathrm{s})}+3 \mathrm{NH}_{3} \mathrm{BH}_{3}(\mathrm{~s}) \rightarrow \mathrm{Na}\left(\mathrm{BH}_{3} \mathrm{NH}_{2} \mathrm{BH}_{2} \mathrm{NH}_{2} \mathrm{BH}_{3}\right)_{(\mathrm{s})}+\mathrm{NH}_{3(\mathrm{~g})}$

In the present study, we survey a power law kinetic model capable of approximately guess the overall $\mathrm{NaABB}$ synthesis. These experiments were carried out at varied temperature ranges from $0^{\circ} \mathrm{C}$ to $24^{\circ} \mathrm{C}$, and varied inlet molar ratios $(\mathrm{AB} / \mathrm{NaH})$ from 0.75 to 1.25 . As a result of parametric studies, the following data has been obtained. The difference of this study from the study of Chen et al, (2015) is that NaABB synthesis in a single feed and low-temperature single reactor, while the difference from the study of Fijalkowski et al. (2014) is that sodium di (amidoborane) borohydride is realized as a by-product just above the stoichiometric inlet molar ratio. Also, GCMS-MS, XRD, and FTIR analyzes were performed for the characterization of the synthesized products.

\section{EXPERIMENTAL SECTION}

\section{Synthesis Experiments}

Sodium hydride (95\% purity) and AB (97\% purity) were Sigma Aldrich products, kept and handled in a nitrogen-filled glove box. These reactants were weighed in the glove box and made ready for the reaction. Then the chemical reaction of $\mathrm{NH}_{3} \mathrm{BH}_{3}$ with $\mathrm{NaH}$ in THF was carried out in a commercial stirring tank reactor at the constant temperature. The data of gas production was collected with volumetric measurements. Next, the reaction solution was filtered, the residue on the filter was washed several times with THF. Then it was removed from THF by remaining in an oven with a vacuum pump connected for sixteen hours at room temperature. All synthesized solid samples were stored in Eppendorf tubes. In the synthesis experiments, the diversity of the products was investigated by changing the $\mathrm{NaH}$ inlet mole ratio. Besides, the effect of temperature on the property of synthesized products was also examined. The calculations in the study conducted in the $\mathrm{NaABB}$ synthesis experiment make according to Equation 5.

$\mathrm{NaH}+2 \mathrm{NH}_{3} \mathrm{BH}_{3} \rightarrow \mathrm{NaNH}_{2}\left(\mathrm{BH}_{3}\right)_{2}+\mathrm{NH}_{3}(\mathrm{~g})+\mathrm{H}_{2}(\mathrm{~g})$

\section{Characterization \\ FT-IR analysis}

Molecular structures of synthesized compounds were characterized by using FT-IR in the range of $400-4000 \mathrm{~cm}^{-1}$ by using $\mathrm{KBr}$ disc method (Perkin Elmer Spectrum One). According to this analysis, synthesized solid products were mixed potassium bromide at the ratio of 1:100 (solid sample: $\mathrm{KBr}$ ) for dilution.

\section{XRD analysis}

The crystallinity of $\mathrm{SAB}$ and $\mathrm{NaABB}$ were investigated using a Rigaku Miniflex 600 powder Xray diffractometer with an in situ cell $(\mathrm{Cu} \mathrm{K} \alpha, 40 \mathrm{kV}$, $15 \mathrm{~mA})$. The data were collected from $10^{\circ}$ to $50^{\circ}$ in 2-theta range $2 \theta$ with a scan step width of 0.01 . The working range was selected according to the data on $\mathrm{SAB}$ in the literature. There is no strong characteristic peak of more than $50^{\circ}$ synthesized products.

\section{GC-MS/MS analysis}

The synthesis reactions were carried out in a closed reactor with a special cap. GC-MS/MS analysis was performed to detect gases released during the synthesis (Thermo Scientific TSQ Duo Triple Quadrupole GC-MS/MS). Gas samples (1 ml volume) were taken with special gas syringes for GC-MS at 3 $\mathrm{min}, 8 \mathrm{~min}$, and $15 \mathrm{~min}$. Thus, it was possible to analyze the gases produced during the reaction.

TR-FAME GC column, $0.25 \mathrm{~mm} \times 120 \mathrm{~m}$ dimensions, was used in GC-MS/MS. Helium, 99.9999\% purity, was flowed into the GC system as a carrier gas and injection type was selected splitless. Besides, the temperature program was $80-250{ }^{\circ} \mathrm{C}$ at $30{ }^{\circ} \mathrm{C} / \mathrm{min}$, the post temperature $250^{\circ} \mathrm{C}$.

\section{RESULTS AND DISCUSSION}

\section{Synthesis experiments results}

In the synthesis experiments carried out at different inlet molar ratios, it was observed that there was an extra gas production in the synthesis with 1.25 inlet molar ratio which was above the stoichiometric ratio. Thereupon, synthesis experiments of the 1,25 ratio synthesis were conducted at $0{ }^{\circ} \mathrm{C}, 12{ }^{\circ} \mathrm{C}$ and 24 ${ }^{\circ} \mathrm{C}$. The data obtained are given in Table 1. Hydrogen was evolved vigorously after dropping $\mathrm{NH}_{3} \mathrm{BH}_{3}-\mathrm{THF}$ solution into the $\mathrm{NaH}-\mathrm{THF}$ solution in the synthesis reaction. For $\mathrm{NaH}$ conversion, firstly, the unreacted mole of $\mathrm{NaH}$ was calculated by using Equation 1. Then it was calculated by dividing the amount of unreacted $\mathrm{NaH}$ with the amount of initial $\mathrm{NaH}$. The efficiency calculation is the percentage equivalent of the ratio of expected gas volume to experimentally measured volume. 
Table 1. $\mathrm{NaH}$ conversions versus the temperature of the experiment conducted

\begin{tabular}{ccccc}
\hline Synthesis temperature, ${ }^{\circ} \mathrm{C}$ & $3 \mathrm{~min}$ & $8 \mathrm{~min}$ & $15 \mathrm{~min}$ & Efficiency, \% \\
\hline 0 & 12 & 59 & 84 & 117 \\
12 & 7 & 74 & 83 & 110 \\
24 & 9 & 75 & 82 & 106 \\
\hline
\end{tabular}

Total $\mathrm{NaH}$ conversion values are $98 \%, 88 \%$, and $85 \%$ at $0^{\circ} \mathrm{C}, 12^{\circ} \mathrm{C}$ and $24^{\circ} \mathrm{C}$, respectively. This synthesis reaction is exothermic. Therefore, as the temperature increases, the synthesis efficiency decreases. The majority of synthesis takes place between 3 and 8 minutes. While $\mathrm{NaH}$ conversion rates were similar in the experiment performed at 12 and $24{ }^{\circ} \mathrm{C}$, a more controlled and slower synthesis occurred at $0{ }^{\circ} \mathrm{C}$. Besides, it seems that the efficiency is quite high for $S A B$ production. Since both $S A B$ and $\mathrm{NaABB}$ are exothermic, a greater amount of production occurred at low temperature.

\section{FTIR analysis results}

$S A B$ and NaABB were characterized by FTIR spectra. The analysis result is shown in Figure 1. In the spectra of $S A B$, absorption peaks from $3000-3500$ $\mathrm{cm}^{-1}$ links to $\mathrm{N}-\mathrm{H}$ stretching, whereas the $\mathrm{B}-\mathrm{H}$ stretching appears in the region $2000-2520 \mathrm{~cm}^{-1}$. Other characteristic peaks in the FTIR analysis of $S A B$, absorption peaks, $\mathrm{B}-\mathrm{H}$ bending appears region at $1000-1300 \mathrm{~cm}^{-1}$, and $\mathrm{N}-\mathrm{H}$ bending appears region at $1300-1800 \mathrm{~cm}^{-1}$. Two strong characteristic peaks of $B N$ were detected in the FT-IR spectrum of $\mathrm{NaABB}$. Of these, seen at a wavelength of $1490 \mathrm{~cm}^{-1}$ the peak is the $\mathrm{B}-\mathrm{N}$ stretching vibration, the peak at $706 \mathrm{~cm}^{-1}$ is the $B-N-B$ bending vibration (Aydın, 2018). It is seen that $B-N$ bond has less effect in $S A B$, besides $B-N-B$ bending vibration is not observed. $\mathrm{NaABB}$ gives peaks in the same regions as $S A B$ but it contains amorphous intense polyborazylene, for evidence by the absorption peaks at $3400 \mathrm{~cm}^{-1}, 1490 \mathrm{~cm}^{-1}$, and $750 \mathrm{~cm}^{-1}$ (Chen et al., 2015). The reason for the $1490 \mathrm{~cm}^{-1}$ region is high is that it coincides with the B-N stretching, $\mathrm{N}-\mathrm{H}$ bending, and unreacted $\mathrm{NaH}$. The $\mathrm{NaH}$ crystal structure is thought to be another reason for a sharper peak than amorphous products. In addition, it is seen that the interaction of $\mathrm{B}-\mathrm{N}$ with other bonds (especially B-H) is high (Sandra, 2011). SAB's N-H and B-H peaks differ lightly from the literature. This is likely by factors such as packing, anion cation interaction or the effect of hydrogen bonding of the synthesized product (Fijalkowski et al., 2014). It is seen that NaABB is more resistant to environmental conditions than $\mathrm{SAB}$. As seen in Figure 1, characteristic peaks appear to be sharper in products with NaABB. In the FTIR characterization of the synthesis products made at different temperatures, it was observed that the sharpness of the peaks disappeared as the temperature increased.

\section{XRD analysis results}

The X-ray diffraction patterns of synthesized are shown in Figure 2. According to XRD results of synthesized products; $S A B$ was determined in syntheses of the initial reactant molar ratio of $A B$ to $\mathrm{NaH} \mathrm{1:1} \mathrm{and} \mathrm{0.75:1.} \mathrm{However,} \mathrm{SAB} \mathrm{and} \mathrm{NaABB}$ were detected in the synthesis of the initial molar ratio of $A B$ to $\mathrm{NaH}$ 1.25:1. There were six characteristic peaks of $\mathrm{NaABB}$ at $19.9^{\circ}, 30.28^{\circ}, 34^{\circ}, 36.74^{\circ}, 38.3^{\circ}$, and $41.9^{\circ}$. In the analysis result, sodium di(amidoborane) borohydride could not be detected. In the XRD analysis of the temperature effect of the syntheses above the stoichiometric molar ratio carried out at different temperatures, there was little difference. It was observed that the synthesis at $0{ }^{\circ} \mathrm{C}$ produced more NaABB than those produced at other temperatures. However, the range studied here is quite limited. Since polymerization will occur in the structure when it is close to the thermolysis temperature, the intensity and location of the peaks are expected to change.

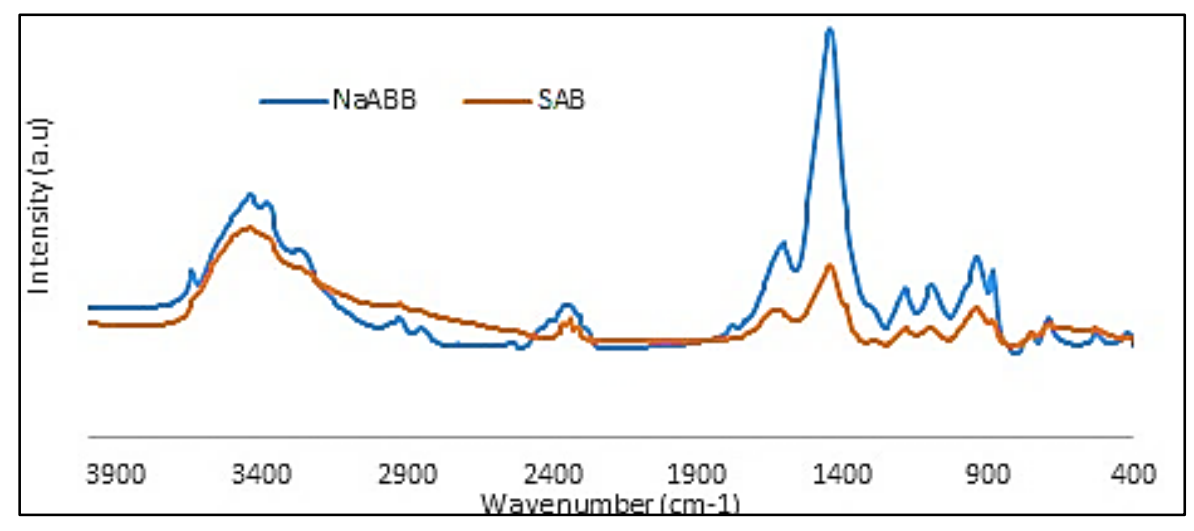

Figure 1. Comparison of FTIR spectra of SAB (orange lines) and NaABB (blue lines) 


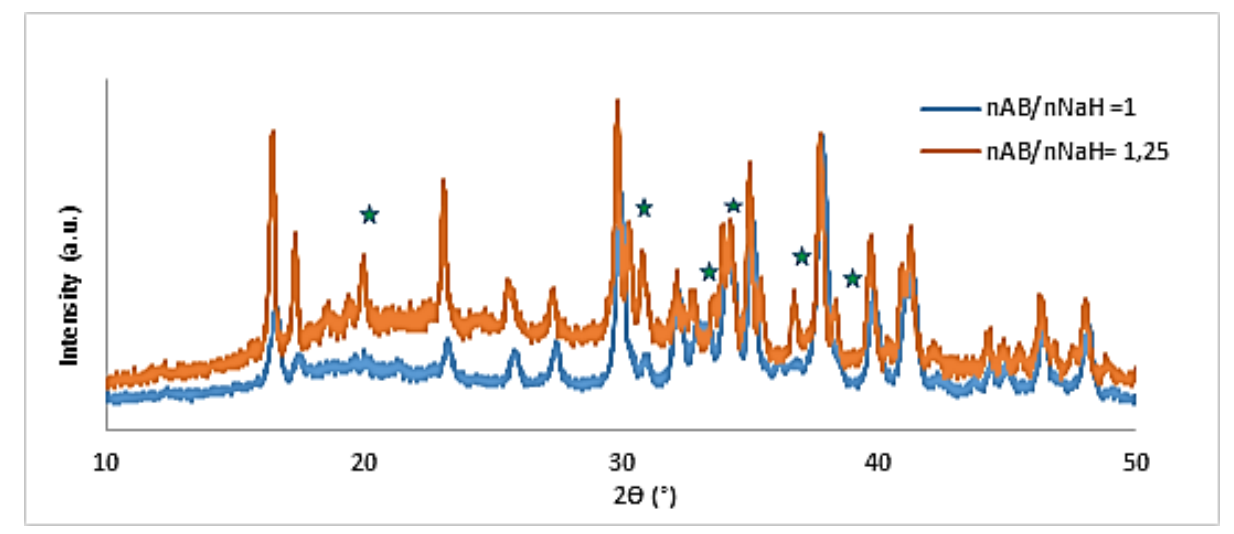

Figure 2. XRD analysis results of synthesized of initial reactive molar ratio $(A B / N a H)=1$ and $(\mathrm{AB} / \mathrm{NaH})=1.25$ (The characteristic peaks of $\mathrm{NaABB}$ are indicated by asterisks.)

\section{GC-MS/MS analysis results}

GC-MS/MS analysis results support FTIR and XRD characterization results. In the GC-MS/MS analysis of stoichiometric synthesized $S A B$, no ammonia was determined, on the other hand, peaks with the retention time of 20-26 minutes were found to belong to THF and furan (THF decomposition product) (Figure 3). THF and furan gave a few peaks in GC. The remnants of previous analyzes were thought to have different adsorption with THF in the column. Moreover, in the GC-MS/MS analysis of synthesized in 1.25 initial reactant ratio, it was determined ammonia (18-22 $\mathrm{min})$, THF and furan $(21-28 \mathrm{~min})$. GC-MS/MS analysis of $\mathrm{NaABB}$ synthesis result is given Figure 4. It was observed that $\mathrm{NaABB}$ given in Eq. 5 with ammonia seen in GC-MS/MS analysis could be produced. There is a situation that needs attention in this analysis. It was determined that THF interacted with the column used, and it started to disrupt the structure of the column. Therefore, GCMS analysis of synthesis experiments at $0{ }^{\circ} \mathrm{C}$ and $12{ }^{\circ} \mathrm{C}$ could not be performed, unfortunately.

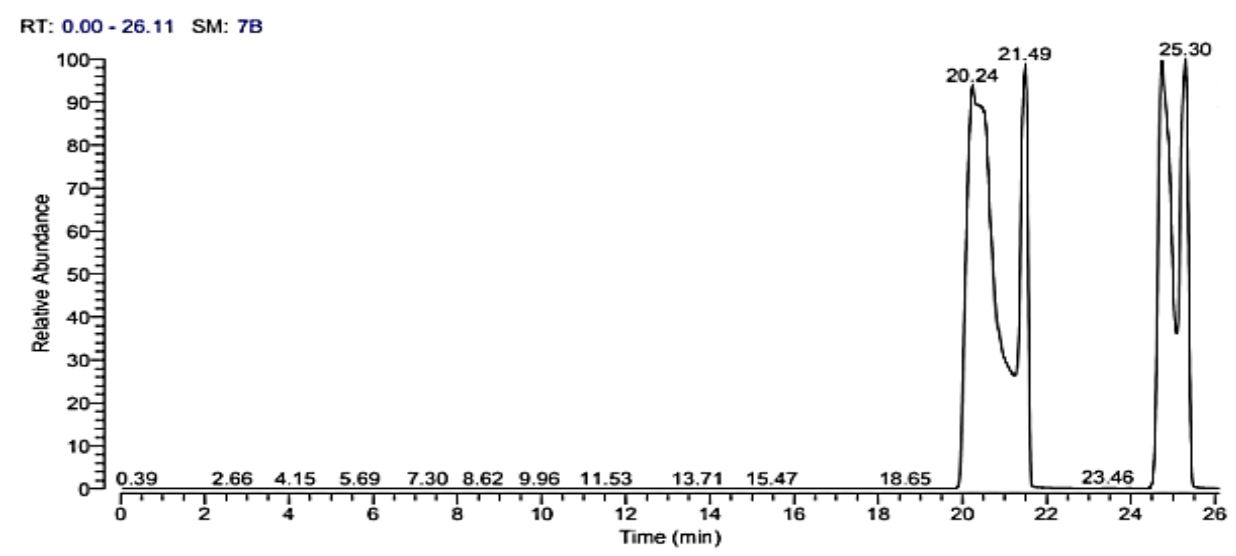

Figure 3. GC-MS/MS analysis of the $S A B$ synthesis

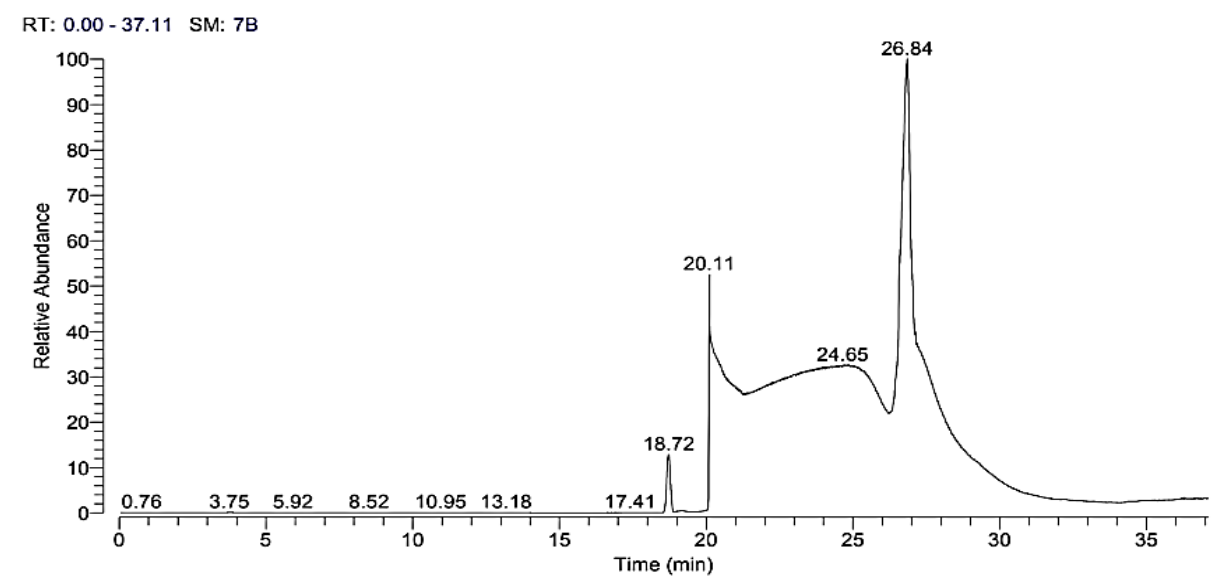

Figure 4. GC-MS/MS analysis of $\mathrm{NaABB}$ synthesis 
It was determined that the mixture of $S A B$ and $\mathrm{NaABB}$ was realized above the stoichiometric ratio. Similarly, it is thought that the synthesis of sodium diamidoborane borohydride with $\mathrm{NaABB}$ will also occur with $A B$ / NaH inlet molar ratio between 2: 1 and 3: 1 .

\section{Kinetic study of sodium aminodiborane's synthesis reaction}

These synthesis experiments were carried out at different temperature ranges between $0{ }^{\circ} \mathrm{C}, 12^{\circ} \mathrm{C}$, and $24{ }^{\circ} \mathrm{C}$, and different initial reactant molar ratios $(\mathrm{AB} / \mathrm{NaH})$ from 0.75 to 1.25 . $\mathrm{NaABB}$ synthesis kinetic reaction was determined by using synthesis data, the power-law model was preferred to determine the synthesis reaction rate in terms of concentrations of reactants. NaABB synthesis was calculated a single reaction step. Therefore, it was regarded that the reaction rate expression follows a power-law (according to Equation 5:

$r_{\text {observed }}=\mathrm{kC}_{\mathrm{AB}}{ }^{\alpha} \mathrm{C}_{\mathrm{NaH}}{ }^{\beta}$ or $\mathrm{r}_{\text {observed }}=\mathrm{kC}_{\mathrm{A}}{ }^{\alpha} \mathrm{C}_{\mathrm{B}}{ }^{\beta}$

where $\alpha$; the reaction order versus the $A B$ concentration $\beta$; the reaction order versus the $\mathrm{NaH}$ concentration. $k$ is the reaction rate constant in the Arrhenius equation:

$\mathrm{k}=\mathrm{k}_{\mathrm{o}} \mathrm{e}^{(-\mathrm{E} / \mathrm{RT})}$

in which $k_{0}$ frequency constant and $E_{a}$ the apparent activation energy. Calculations were made according to the constant volume batch reactor design equation. According to this design, $\mathrm{NaH}$ mole equivalence was

$r_{\mathrm{NaH}} V=\frac{d\left(n_{\mathrm{NaH}}\right)}{d t}$

$r=\frac{d\left(C_{\mathrm{NaH}}\right)}{d t}=-k C_{A B}^{\alpha} C_{N a H}^{\beta}$

$C_{A}=C_{A o}-C_{A o} X_{A}=C_{A o}\left(1-X_{A}\right)$ and $C_{B}=C_{B o}-C_{A o} X_{A}$

$C_{A o}$ is $C_{0}$ times of $C_{B o}$, so $C_{B o}=C_{o} C_{A o}$

$$
\begin{aligned}
& C_{B}=C_{A o} C_{o}-C_{A o} X_{A}=C_{A o}\left(C_{o}-0.5 X_{A}\right) d C_{A o}\left(1-X_{A}\right) / \\
& d t=-k\left[C_{A o}\left(1-X_{A}\right)\right]^{\alpha}\left[C_{A o}\left(C_{o}-0.5 X_{A}\right)\right]^{\beta} \\
& \frac{\mathrm{d} X_{A}}{\left(1-X_{A}\right)^{\alpha}\left(C o-0.5 X_{A}\right)^{\beta}}=k C_{A o}^{(\alpha+\beta-1)} d t \\
& \left(\frac{\mathrm{a}}{\left(1-\mathrm{X}_{\mathrm{A}}\right)^{\alpha}}+\frac{\mathrm{b}}{\left(\mathrm{C}_{o}-0.5 \mathrm{X}_{\mathrm{A}}\right)^{\beta}}\right) \mathrm{d} \mathrm{X}_{\mathrm{A}}=\mathrm{k} \mathrm{C}_{\mathrm{A}_{o}}^{(\alpha+\beta-1)} \mathrm{dt}
\end{aligned}
$$

By solving Equation 10 with partial integration, find the coefficients $a$ and $b$ in Equation 11.

$\left[a(1-\beta)\left(1-X_{A}\right)^{(1-\alpha)}+2 b(1-\alpha)\left(C_{O}-0.5 X_{A}\right)^{(1-\beta)}\right]=[a(1-$ $\left.\beta)+2 b(1-\alpha)\left(C_{O}\right)^{(1-\beta)}\right]-k(1-\alpha)(1-\beta) C_{A 0}^{(\alpha+\beta-1)}+$ (15)

Equation 15 supply a base for integral analysis of constant volume batch reactor data; a plot of which (the right side of equality, versus time) could give rise to straight lines, giving $k$, $\alpha$, and $B$. On this basis, firstly the overall reaction order is resolved, then relevant experimental data, $\alpha$ and $\beta$ values are ascertained using by Equation 15. $R^{2}$ values were calculated using the equation by using various $\alpha$ and $B$ assumption for each experiment. The NaABB synthesis carried out above the stoichiometric ratio, therefore $\mathrm{C}_{0}$ value was taken as 1.25 in the experiments. Among the assumptions made, the case with the highest $R^{2}$ value is $\alpha=0.8$ and $\beta=0.2$.

Table 2 shows assumption results. As a result, the $\mathrm{NaABB}$ synthesis reaction degree $\alpha$ and $\beta$ values were found to be 0.8 and 0.2 , respectively. Figure 5 illustrates graphs are plotted on the data on the right side of Eq. 15 by using experimental data at different temperature versus time. According to this assumption, it has a high $R^{2}$ value for $C_{0}=1$ and $C_{0}$ $=1.25$, also. $A B$ was determined to have a great effect on the synthesis reactions.

According to the data of the $\mathrm{NaABB}$ synthesis experiment, which was carried out 1.25 inlet ratio, $\mathrm{k}$ value was determined for each temperature (Table 3).

Table 2. $R^{2}$ outcomes for diverse $\alpha$ or $\beta$ values

\begin{tabular}{lllllll}
\hline \multicolumn{7}{c}{ Experimental Conditions, $\left(\mathrm{C}_{\circ}=\frac{n_{A B}}{n_{N a H}}\right)$} \\
\hline$\alpha$ & $\beta$ & $0^{\circ} \mathrm{C}, \mathrm{C}_{\circ}=1.25$ & $12^{\circ} \mathrm{C}, \mathrm{C}_{\circ}$ & $=24^{\circ} \mathrm{C}, \mathrm{C}_{\circ}$ & $=24^{\circ} \mathrm{C}, \mathrm{C}_{\circ}=0.75$ & $24{ }^{\circ} \mathrm{C}, \mathrm{C}_{\circ}=1$ \\
& & 1.25 & 1.25 & & \\
\hline 0.1 & 0.9 & 0.9823 & 0.9028 & 0.9842 & 0.9868 & 0.9970 \\
0.2 & 0.8 & 0.9837 & 0.8514 & 0.9803 & 0.9886 & 0.9833 \\
0.3 & 0.7 & 0.9754 & 0.8893 & 0.9900 & 0.9950 & 0.9734 \\
0.4 & 0.6 & 0.9604 & 0.8828 & 0.9902 & 0.9956 & 0.9597 \\
0.5 & 0.5 & 0.9399 & 0.8758 & 0.9881 & 0.9936 & 0.9444 \\
0.6 & 0.4 & 0.9149 & 0.8684 & 0.9871 & 0.9927 & 0.9279 \\
0.7 & 0.3 & 0.8867 & 0.8603 & 0.9842 & 0.9911 & 0.9106 \\
0.8 & 0.2 & 0.9874 & 0.9897 & 0.9892 & 0.9956 & 0.9857 \\
0.9 & 0.1 & 0.8245 & 0.8415 & 0.9753 & 0.9846 & 0.9317 \\
\hline
\end{tabular}

Table 3. Kinetic parameters for sodium aminodiborane synthesis, $r=k[A B]^{\alpha}[\mathrm{NaH}]^{\beta}$

\begin{tabular}{cccc}
\hline Temperature, ${ }^{\circ} \mathrm{C}$ & $\mathrm{k}, h^{-1}$ & $\alpha$ & $b$ \\
\hline 0 & 0.1462 & 0.8 & 0.2 \\
12 & 0.1368 & 0.8 & 0.2 \\
24 & 0.1506 & 0.8 & 0.2 \\
\hline
\end{tabular}


(a)

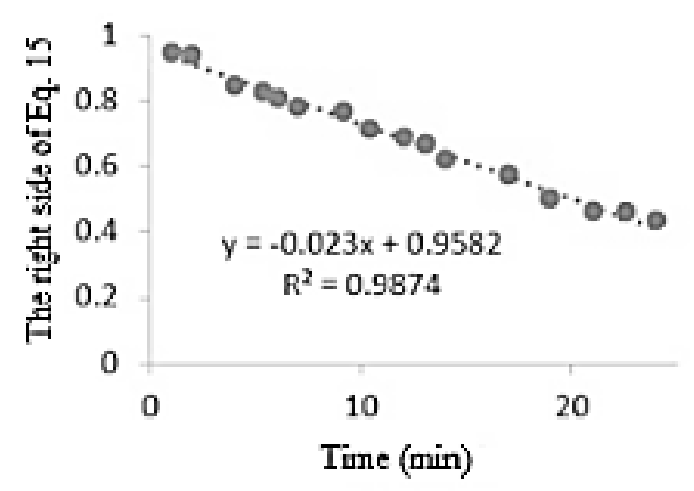

(b)

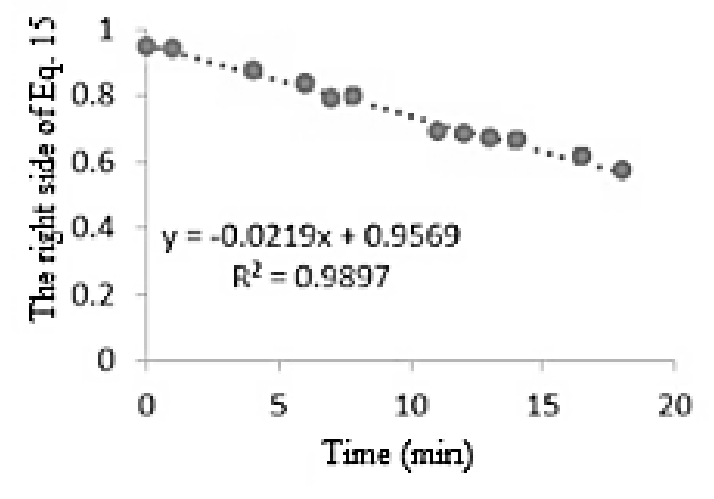

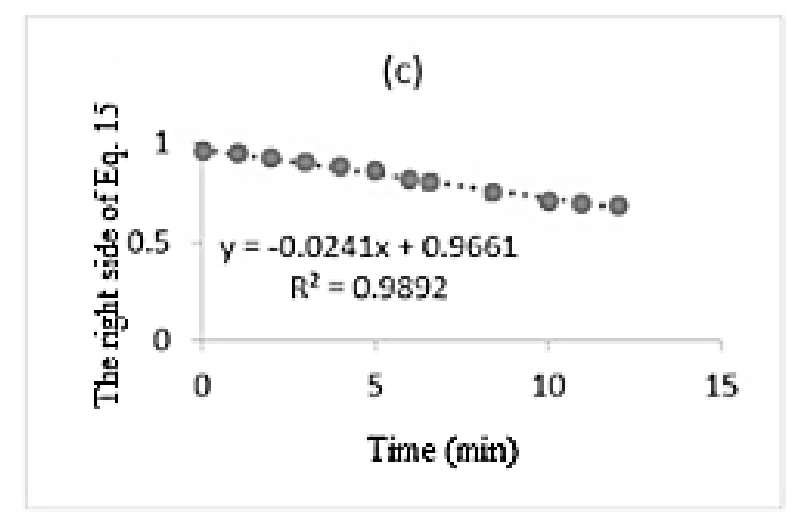

Figure 5. Plots of the right side of Equation 15 versus time (a) using experimental data at $\mathrm{T}=0{ }^{\circ} \mathrm{C}$, (b) using experimental data at $\mathrm{T}=12{ }^{\circ} \mathrm{C}$, (c) using experimental data of $\mathrm{T}=24^{\circ} \mathrm{C}$ and $\mathrm{C}_{0}=1.25 \alpha=0.8$ and $\beta=0.2$.

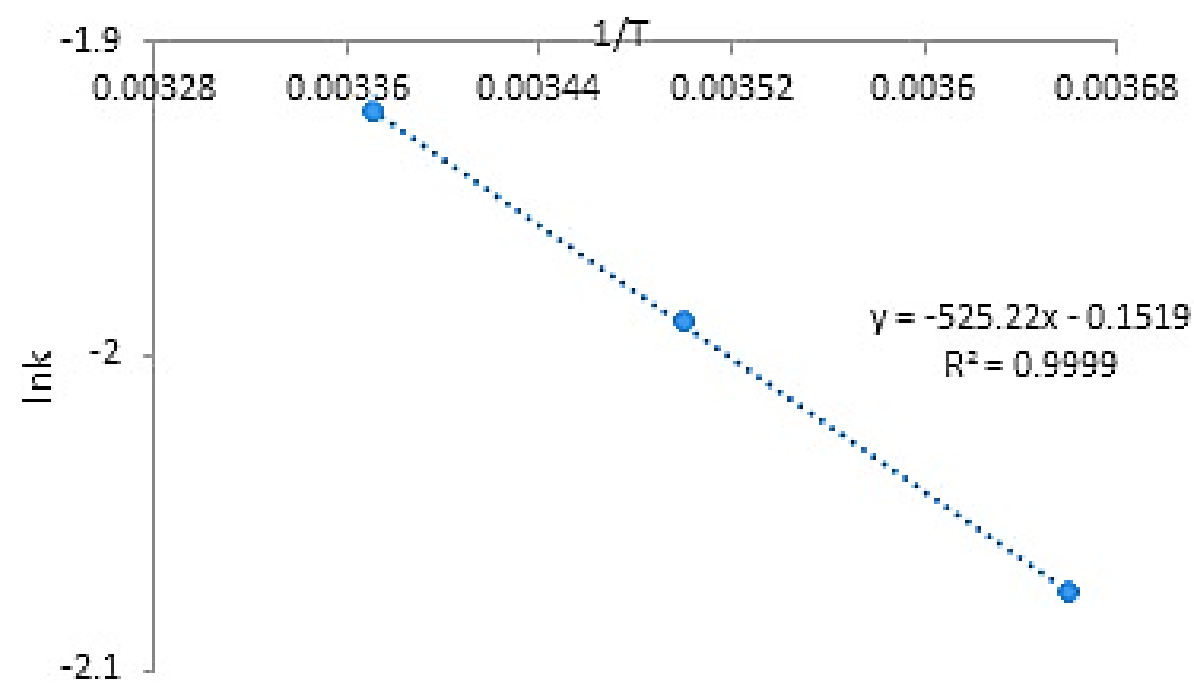

Figure 6. The graph of $1 / T$ versus $\ln (k)$

Figure 6 illustrates $\ln (\mathrm{k})$ values versus $1 / \mathrm{T}$. As shown in Figure 6, the value of $R^{2}$ is quite high. Ea was determined from $\mathrm{NaABB}$ synthesis data at $0^{\circ} \mathrm{C}$, $12^{\circ} \mathrm{C}$ and $24^{\circ} \mathrm{C}$. Utmost attention should be paid to the synthesis being exothermic the temperature inside the reactor increases.
According to the calculation, Ea and $\mathrm{k}_{\mathrm{o}}$ values were found as $4366 \mathrm{~J} / \mathrm{mol}$ and $0.8594 \mathrm{~h}^{-1}$, respectively. The observed the synthesis reaction rate expression is given Equation 16. The kinetic parameters' estimates are given Table 4.

$r_{\text {apparent }}=0.8594 \mathrm{e}^{-\frac{4366}{\mathrm{RT}}} \mathrm{C}_{\mathrm{AB}}^{0.8} \mathrm{C}_{\mathrm{NaH}}^{0.2}$ 
Table 4. Estimates of kinetic parameters

\begin{tabular}{cc}
\hline Parameter & Estimates \\
\hline$\alpha$ & $0.8 \pm 0.008$ \\
$\beta$ & $0.2 \pm 0.002$ \\
$k_{\circ}$ & $0.8594 \pm 0.71 \mathrm{~h}^{-1}$ \\
$E_{a}$ & $4366 \pm 66 \mathrm{~J} / \mathrm{mol}$ \\
\hline
\end{tabular}

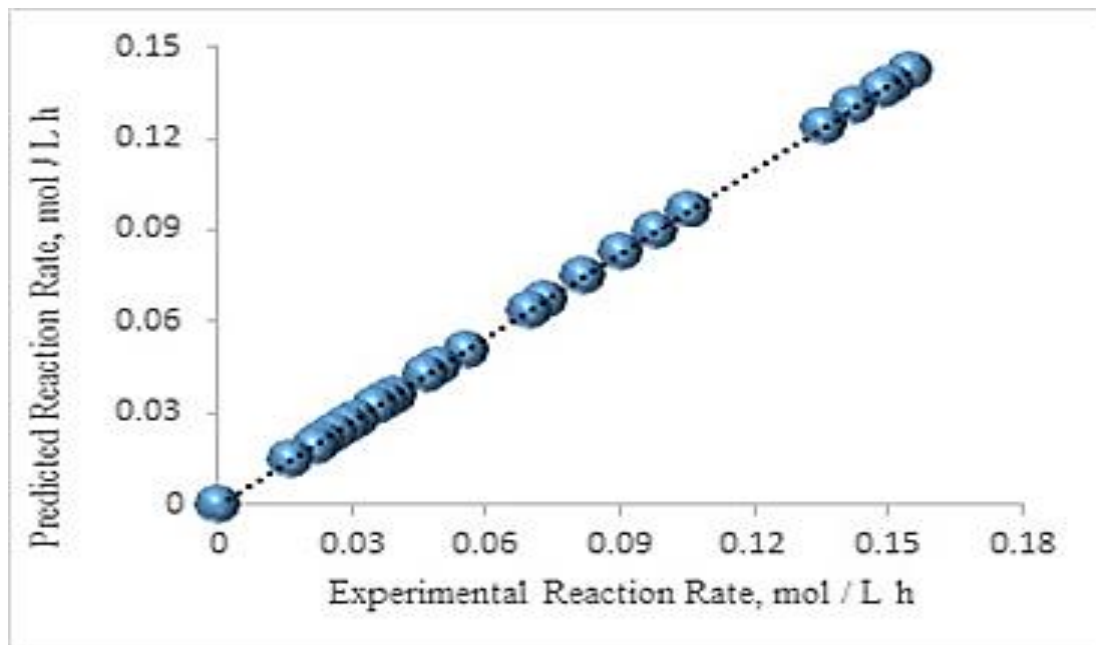

Figure 7. Predicted reaction rate versus experimental reaction rate

In Figure 7, the NaABB synthesis rate equation determined using the power-law model rate expression shows that it is within the error of $10 \%$. Therefore, reliability of the proposed rate equation is improving.

The missing aspect of this study is the acceptance of the NaABB synthesis kinetic calculation to be valid in the synthesis of 1.25 initial reactant molar ratio and overall reaction. This study was calculated to give preliminary information for NaABB synthesis kinetics. $\mathrm{NaABB}$ was synthesized at a lower temperature and a single step reaction compared to the study of Chen et. al (Chen et al., 2015). Therefore, it can be widely used as hydrogen storage material.

\section{CONCLUSIONS}

$S A B$ is a hydrogen storage material that has been studied extensively in recent times. It is possible to synthesize new high hydrogen capacity materials through the $\mathrm{B}-\mathrm{H}$ group in the structure of this material. Using this bond, complexation occurs in the structure. If $\mathrm{NaABB}$ is synthesized from $\mathrm{NaH}$ and $A B$, the ammonia concentration is lower than that synthesized by $\mathrm{NaNH}_{2}$ and $\mathrm{AB}$. Moreover, it is possible to synthesize $\mathrm{NaABB} N \mathrm{NaH}$ and $A B$ in a single step and in a shorter time by increasing the concentration of $\mathrm{AB}$. In the experiments, sodium di(amidoborane) borohydride could not be detected. GC-MS/MS, XRD and FTIR analyses were performed to show this. Subsequent studies will examine whether NaABB's conversion to sodium di(amidoborane)borohydride is possible.
Besides, the reaction kinetic of $\mathrm{NaABB}$ (1.25 initial reactant molar ratio) in the THF medium was calculated. According to this, $r_{\text {apparent }}=$ $0.8594 \mathrm{e}^{-\frac{4366}{\mathrm{RT}}} \mathrm{C}_{\mathrm{AB}}^{0.8} \mathrm{C}_{\mathrm{NaH}}^{0.2}$. $\mathrm{E}_{\mathrm{a}}$ and $\mathrm{k}_{\mathrm{o}}$ were calculated about $4366 \mathrm{~J} / \mathrm{mol}$ and $0.8594 \mathrm{~h}^{-1}$, respectively. Predicted NaABB synthesis rate equation determined using the power-law model rate expression shows that it is within the error of $10 \%$. Moreover, this synthesis reaction was found to have higher yields at lower temperatures because of exothermic reaction.

\section{REFERENCES}

Akbayrak, S., \& Özkar, S. (2018). Ammonia borane as hydrogen storage materials. International Journal of Hydrogen Energy, 43(40), 1859218606. doi:https://doi.org/10.1016/ i.iihydene.2018.02.190

Akkuş, M. S., Murathan, H. B., Özgür, D. Ö., Özkan, G., \& Özkan, G. (2018). New insights on the mechanism of vapour phase hydrolysis of sodium borohydride in a fed-batch reactor. International Journal of Hydrogen Energy, 43(23), 10734-10740. doi:https://doi.org/ 10.1016/j.ijhydene.2018.01.177

Au, M., \& Jurgensen, A. (2006). Modified Lithium Borohydrides for Reversible Hydrogen Storage. The Journal of Physical Chemistry B, 110(13), 7062-7067. doi:10.1021/ip056240。

Aydın, H. (2018). Nanoyapılı Hegzagonal Bor Nitrür Üretimi ve Karakterizasyonu. Firat Üniversitesi Mühendislik Bilimleri Dergisi, 30(2), 269-275. 
Brack, P., Dann, S., \& Wijayantha, K. (2015). Heterogeneous and homogenous catalysts for hydrogen generation by hydrolysis of aqueous sodium borohydride $\left(\mathrm{NaBH}_{4}\right)$ solutions. Energy Science and

Engineering. doi:10.1002/ese3.67/abstract

Chen, W., Huang, Z., Wu, G., \& Chen, P. (2015). New synthetic procedure for $\mathrm{NaNH}_{2}\left(\mathrm{BH}_{3}\right)_{2}$ and evaluation of its hydrogen storage properties. Science China Chemistry, 58(1), 169-173. doi: 10.1007/s 11 1426-014-5268-7

Fan, Y., Chen, D., Liu, X., Fan, G., \& Liu, B. (2019). Improving the hydrogen storage performance of lithium borohydride by $\mathrm{Ti}_{3} \mathrm{C}_{2}$ MXene. International Journal of Hydrogen Energy, 44(55), 29297-29303. doi:https://doi.org/10.1016/i.ijhydene.2019.0 1.011

Fijałkowski, K. J., \& Grochala, W. (2009). Substantial emission of $\mathrm{NH} 3$ during thermal decomposition of sodium amidoborane, $\mathrm{NaNH}_{2} \mathrm{BH}_{3}$. Journal of Materials Chemistry, 19(14), 2043-2050. doi:10.1039/B813773K

Fijalkowski, K. J., Jaroń, T., Leszczyński, P. J., MagosPalasyuk, E., Palasyuk, T., Cyrański, M. K., \& Grochala, W. (2014). $\mathrm{M}\left(\mathrm{BH}_{3} \mathrm{NH}_{2} \mathrm{BH}_{2} \mathrm{NH}_{2} \mathrm{BH}_{3}\right)-$ the missing link in the mechanism of the thermal decomposition of light alkali metal amidoboranes. Physical Chemistry Chemical Physics, 16(42), 23340-23346. doi: 10.1039/C4CP03296A

Huang, Z., \& Autrey, T. (2012). Boron-nitrogenhydrogen $(\mathrm{BNH})$ compounds: recent developments in hydrogen storage, applications in hydrogenation and catalysis, and new syntheses. Energy \& Environmental Science, 5(11), 9257-9268. doi: 10.1039/C2EE23039A

Hügle, T., Kühnel, M. F., \& Lentz, D. (2009). Hydrazine Borane: A Promising Hydrogen Storage Material. Journal of the American Chemical Society, 131(21), 7444-7446. doi:10.1021/ja9013437

Keaton, R. J., Blacquiere, J. M., \& Baker, R. T. (2007). Base Metal Catalyzed Dehydrogenation of Ammonia-Borane for Chemical Hydrogen Storage. Journal of the American Chemical Society, 129(7), 1844-1845. doi: 10.1021/ja066860i

Kojima, Y., Kawai, Y., Kimbara, M., Nakanishi, H., \& Matsumoto, S. (2004). Hydrogen generation by hydrolysis reaction of lithium borohydride. International Journal of Hydrogen Energy, 29(12), 1213-1217. doi:https://doi.org/ 10.1016/i.ijhydene.2003.12.009

Li, C., Peng, P., Zhou, D. W., \& Wan, L. (2011). Research progress in $\mathrm{LiBH} 4$ for hydrogen storage: A review. International Journal of Hydrogen Energy, 36(22), 14512-14526. doi:https://doi.org/10.1016/i.ijhydene.2011.0 8.030

Liu, B. H., Li, Z. P., \& Suda, S. (2009). Solid sodium borohydride as a hydrogen source for fuel cells. Journal of Alloys and Compounds, 468(1), 493498.doi:https://doi.org/10.1016/i.jallcom.20 08.01 .023

Magos-Palasyuk, E., Fijalkowski, K. J., \& Palasyuk, T. (2016). Chemically driven negative linear compressibility in sodium amidoborane, $\mathrm{Na}(\mathrm{NH} 2 \mathrm{BH} 3)$. Scientific Reports, 6(1), 28745. doi:10.1038/srep28745

Moury, R., Moussa, G., Demirci, U. B., Hannauer, J., Bernard, S., Petit, E., . . . Miele, P. (2012). Hydrazine borane: synthesis, characterization, and application prospects in chemical hydrogen storage. Physical Chemistry Chemical Physics, 14(5), doi: 10.1039/C2CP23403C

1768-1777.

Muthu, R. N., Rajashabala, S., \& Kannan, R. (2017). Hydrogen storage performance of lithium borohydride decorated activated hexagonal boron nitride nanocomposite for fuel cell applications. International Journal of Hydrogen Energy, 42(23), 15586-15596. doi:https://doi.org/10.1016/i.ijhydene.2017.0 4.240

Owarzany, R., Leszczyński, J. P., Fijalkowski, J. K., \& Grochala, W. (2016). Mono- and Bimetalic Amidoboranes. Crystals, 6(8). doi:10.3390/ cryst6080088

Özkan, G., Akkuş, M. S., \& Özkan, G. (2019). The effects of operating conditions on hydrogen production from sodium borohydride using Box-Wilson optimization technique. International Journal of Hydrogen Energy, 44(20), 9811-9816. doi:https://doi.org/ 10.1016/i.ijhydene.2018.12.134

Peng, B., \& Chen, J. (2008). Ammonia borane as an efficient and lightweight hydrogen storage medium. Energy \& Environmental Science, 1(4), 479-483. doi:10.1039/B809243P

Qiu, S., Sun, L., \& Xu, F. (2015). Metal Amidoboranes and Their Derivatives for Hydrogen Storage (pp. 53-93).

Sandra, F. P. R., Demirci, U. B., Chiriac, R., Moury, R., \& Miele, P. (2011). A simple preparation method of sodium amidoborane, highly efficient derivative of ammonia borane dehydrogenating at low temperature. International Journal of Hydrogen Energy, 36(13),7423-7430. doi:https://doi.org/ 10.1016/i.ijhydene.2011.04.020

Sutton, A. D., Burrell, A. K., Dixon, D. A., Garner, E. B., Gordon, J. C., Nakagawa, T., . . . Vasiliu, M. (2011). Regeneration of Ammonia Borane Spent Fuel by Direct Reaction with Hydrazine and Liquid Ammonia. Science, 331 (6023), 1426. doi:10.1126/science. 1199003 
Umegaki, T., Yan, J.-M., Zhang, X.-B., Shioyama, H., Kuriyama, N., \& Xu, Q. (2009). Boron- and nitrogen-based chemical hydrogen storage materials. International Journal of Hydrogen Energy, 34(5), 2303-2311. doi:https://doi.org/ 10.1016/i.ijhydene.2009.01.002

Weng, B., Wu, Z., Li, Z., \& Yang, H. (2012). Hydrogen generation from hydrolysis of $\mathrm{NH}_{3} \mathrm{BH}_{3} / \mathrm{MH}(\mathrm{M}$ $=\mathrm{Li}, \mathrm{Na}$ ) binary hydrides. International Journal of Hydrogen Energy, 37, 5152-5160. doi:10.1016/i.ïhydene.2011.12.071

Xiong, Z., Wu, G., Chua, Y. S., Hu, J., He, T., Xu, W., \& Chen, P. (2008). Synthesis of sodium amidoborane $\left(\mathrm{NaNH}_{2} \mathrm{BH}_{3}\right)$ for hydrogen production. Energy \& Environmental Science, 1(3), 360-363. doi:10.1039/B805649H

Yot, P. G., Yadav, V., Ould Amara, S., Itiè, J.-P., Demirci, U. B., \& Maurin, G. (2018). Unraveling the mechanical behaviour of hydrazine borane $\left(\mathrm{NH}_{2}-\mathrm{NH}_{2}-\mathrm{BH}_{3}\right)$. Physical Chemistry Chemical Physics, 20(4), 2845-2850. doi:10.1039/C7CP08291F

Zhong, D.-C., Aranishi, K., Singh, A. K., Demirci, U. B., \& Xu, Q. (2012). The synergistic effect of Rh$\mathrm{Ni}$ catalysts on the highly-efficient dehydrogenation of aqueous hydrazine borane for chemical hydrogen storage. Chemical Communications, 48(98), 11945-11947. doi:10.1039/C2CC36407G 